INTERNATIONAL JOURNAL
PHARMACEUTICAL SCIENCES
PESEARCH
RESTI

Received on 10 July 2019; received in revised form, 22 February 2020; accepted, 28 March 2020; published 01 June 2020

\title{
FORMULATION AND IN-VITRO EVALUATION OF CONTROLLED RELEASE MATRIX TABLETS OF LORNOXICAM
}

\author{
P. Suresh Kumar ${ }^{*}$ and A. Sravani
}

Department of Pharmaceutics, Browns College of Pharmacy, Khammam - 507305, Telangana, India.

Keywords:

Lornoxicam, Guar gum, Xanthan gum, Carbopol 934, Controlled release tablets

\section{Correspondence to Author:}

Dr. P. Suresh Kumar

HOD of Pharmaceutics, Browns College of Pharmacy Khammam - 507305, Telangana, India.

\begin{abstract}
The aim of the present study was to develop a controlled release formulation of Lornoxicam to maintain constant therapeutic levels of the drug for over $12 \mathrm{~h}$. Guar gum, xantham gum, and carbopol 934 were employed as polymers. All the formulations were passed various physicochemical evaluation parameters, and they were found to be within limits. From the dissolution studies, it was evident that the formulation (F2) showed better and desired drug release patterns, i.e., $99.65 \%$ in 12 h. It contains the guar gum polymer. It followed the Higuchi order release kinetics mechanism.
\end{abstract}

E-mail: Surae81@gmail.com

INTRODUCTION: Historically, oral drug administration has been the predominant route for drug delivery. It is known to be the most popular route of drug administration due to the fact the gastrointestinal physiology offers more flexibility in dosage form design than most other routes. A major challenge for the pharmaceutical industry in drug development is to produce safe and efficient drugs; therefore, properties of drugs and the way in which they are delivered must be optimized ${ }^{1}$. A controlled release drug delivery system delivers the drug locally or systemically at a predetermined rate for a specified period of time. The goal of such systems is to provide desirable delivery profiles that can achieve therapeutic plasma levels. Drug release is dependent on polymer properties; thus, the application of these properties can produce well characterized, and reproducible dosage forms ${ }^{2}$.

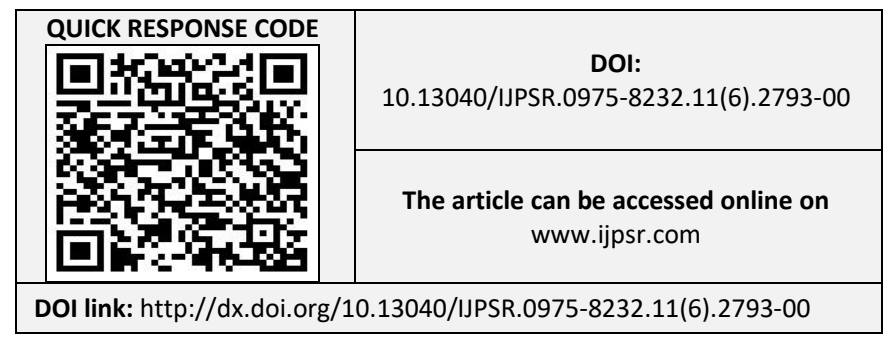

Lornoxicam is a nonsteroidal anti-inflammatory drug (NSAID) with analgesic and antipyretic properties. Prostaglandins are substances that contribute to inflammation of joints. Lornoxicam inhibits prostaglandin synthetase (cylooxygenase 1 and 2) and leads to a decrease in the synthesis of prostaglandins; therefore, inflammation is reduced 3. The aim of the study is to the formulation and invitro characterization of controlled release matrix tablets of Lornoxicam.

MATERIALS AND METHODS: Lornoxicam was a gift sample from (Aurobindo Pharmaceuticals Limited, Hyderabad, India). Carbopol 971P, Xanthan Gum and Guar Gum were obtained from Hetro Pharmaceuticals, Hyderabad, India). Talc, Magnesium stearate, and Microcrystalline cellulose was procured from Loba Chemie Private Ltd. All other chemicals and reagents were analytical grade and used as received.

\section{Fourier Transform Infrared (FTIR)} Spectroscopy: The formulations were subjected to FT-IR studies to find out the possible interaction between the drug and the excipients during the time of preparation. FTIR analysis of the Pure drug and 
optimized formulation was carried out using an FT IR spectrophotometer (Bruker FT-IR - USA) ${ }^{4}$.

Preformulation Parameters: The quality of the tablet, once formulated by rule, is generally dictated by the quality of physicochemical properties of blends.

There are many formulations and process variables involved in mixing, and all these can affect the characteristics of blends produced. The various characteristics of blends tested as per Pharmacopeia 5, 6, 7
Formulation Development of Tablets: All the formulations were prepared by direct compression. The compositions of different formulations are given in Table 1. The tablets were prepared as per the procedure given below, and the aim is to prolong the release of Lornoxicam. Lornoxicam and all other ingredients were individually passed through sieve no ${ }^{1} 60$. All the ingredients were mixed thoroughly by triturating up to $15 \mathrm{~min}$. The powder mixture was lubricated with talc. The tablets were prepared by using direct compression method $^{8}$.

TABLE 1: FORMULATION COMPOSITION FOR MUCOADHESION TABLETS

\begin{tabular}{cccccccccc}
\hline Ingredients & F1 & F2 & F3 & F4 & F5 & F6 & F7 & F8 & F9 \\
\hline Lornoxicam & 8 & 8 & 8 & 8 & 8 & 8 & 8 & 8 & 8 \\
Guar Gum & 4 & 8 & 12 & - & -0 & - & - & - & - \\
Xanthan gum & - & - & - & 4 & 8 & 12 & - & - & - \\
Carbopol 934 & - & - & - & - & - & - & 4 & 8 & 12 \\
PVP K-30 & 10 & 10 & 10 & 10 & 10 & 10 & 10 & 10 & 10 \\
Mg. Stearate & 3 & 3 & 3 & 3 & 3 & 3 & 3 & 3 & 3 \\
Talc & 3 & 3 & 3 & 3 & 3 & 3 & 3 & 3 & 3 \\
MCC PH 102 & 72 & 68 & 64 & 72 & 68 & 64 & 72 & 68 & 64 \\
Total Weight & 100 & 100 & 100 & 100 & 100 & 100 & 100 & 100 & 100 \\
\hline
\end{tabular}

Evaluation of Post Compression Parameters for Prepared Tablets: The designed formulation tablets were studied for their physicochemical properties like weight variation, hardness, thickness, friability, and drug content.

Weight Variation Test: To study the weight variation, twenty tablets were taken, and their weight was determined individually and collectively on a digital weighing balance. The average weight of one tablet was determined from the collective weight. The weight variation test would be a satisfactory method of determining the drug content uniformity. Not more than two of the individual weights deviate from the average weight by more than the percentage shown in the following table, and none deviate by more than twice the percentage. The mean and deviation were determined. The percent deviation was calculated using the following formula ${ }^{9}$.

$\%$ Deviation $=$ Individual weight - Average weight $/$ Average weight $\times 100$

Hardness: Hardness of tablet is defined as the force applied across the diameter of the tablet in order to break the tablet. The resistance of the tablet to chipping, abrasion, or breakage under the condition of storage transformation and handling before usage depends on its hardness. For each formulation, the hardness of three tablets was determined using Monsanto hardness tester, and the average is calculated and presented with deviation ${ }^{10}$.

Thickness: Tablet thickness is an important characteristic of reproducing appearance. Tablet thickness is an important characteristic in reproducing appearance. The average thickness for core and coated tablets is calculated and presented with deviation ${ }^{11}$.

Friability: It is measured by mechanical strength of tablets. Roche friabilator was used to determine the friability by the following procedure. Pre weighed tablets were placed in the friabilator. The tablets were rotated at $25 \mathrm{rpm}$ for $4 \mathrm{~min}(100$ rotations) ${ }^{12}$. At the end of test, the tablets were re weighed, loss in the weight of tablet is the measure of friability and is expressed in percentage as

$$
\% \text { Friability }=\left[\left(\mathrm{W}_{1}-\mathrm{W}_{2}\right) / \mathrm{W}\right] \times 100
$$

Where, $\mathrm{W}_{1}=$ Initial weight of three tablets, $\mathrm{W}_{2}=$ Weight of the three tablets after testing

Determination of Drug Content: Tablets were tested for their drug content. Ten tablets were finely powdered quantities of the powder 
equivalent to one tablet weight of drugs were accurately weighed, transferred to a $100 \mathrm{ml}$ volumetric flask containing $50 \mathrm{ml}$ water, and were allowed to stand to ensure complete solubility of the drug. The mixture was made up to volume with media. The solution was suitably diluted, and the absorption was determined by UV-Visible spectrophotometer. The drug concentration was calculated from the calibration curve ${ }^{13}$.

\section{In-vitro Drug Release Studies:} Dissolution Parameters:

Apparatus: USP-II, Paddle Method

Dissolution Medium: $0.1 \quad \mathrm{~N} \quad \mathrm{HCl}, \quad \mathrm{pH} \quad 6.8$ Phosphate buffer

RPM: 50

Sampling Intervals (h): $0.5,1,2,3,4,5,6,7,8$, $10,11,12$

Temperature: $37^{\circ} \mathrm{C}+0.5^{\circ} \mathrm{C}$

Procedure: $900 \mathrm{ml}$ of $0.1 \mathrm{HCl}$ was placed in a vessel, and the USP apparatus -II (Paddle Method) was assembled. The medium was allowed to equilibrate to temp of $37{ }^{\circ} \mathrm{C}+0.5^{\circ} \mathrm{C}$. Tablet was placed in the vessel, and apparatus was operated for $2 \mathrm{~h}$, and then the media $0.1 \mathrm{~N} \mathrm{HCl}$ were removed, and $\mathrm{pH} 6.8$ phosphate buffer was added process was continued from up to $12 \mathrm{~h}$ at $50 \mathrm{rpm}$.

A definite time intervals withdrawn $5 \mathrm{ml}$ of sample, filtered and again $5 \mathrm{ml}$ media was replaced. Suitable dilutions were done with media and analyzed by spectrophotometrically at respective wavelengths using UV-spectro-photometer ${ }^{14,15,16}$.

Application of Release Rate Kinetics to Dissolution Data: Various models were tested for explaining the kinetics of drug release.

To analyze the mechanism of the drug release rate kinetics of the dosage form, the obtained data were fitted into zero-order, first-order, Higuchi, and Korsmeyer-Peppas release model ${ }^{17,18,19,20}$.

Zero Order Release Rate Kinetics: To study the zero-order release kinetics, the release rate data are fitted to the following equation ${ }^{15}$.

$$
\mathrm{F}=\mathrm{Kot}
$$

Where ' $\mathrm{F}$ ' is the drug release at time' $\mathrm{t}$ ' and ' $\mathrm{Ko}$ ' is the zero-order release rate constant. The plot of $\%$ drug release versus time is linear.

First Order Release Rate Kinetics: The release rate data are fitted to the following equation

$$
\log (100-\mathrm{F})=\mathrm{kt}
$$

A plot of cumulative log percent of drug remaining to be released $v s$. time is plotted, then it gives firstorder release.

Higuchi Release Model: To study the Higuchi release kinetics, the release rate data were fitted to the following equation.

$$
\mathrm{F}=\mathrm{kt}_{1 / 2}
$$

Where ' $\mathrm{k}$ ' is the Higuchi constant. In Higuchi model, a plot of \% drug release versus square root of time is linear.

Korsmeyer and Peppas Release Model: The mechanism of drug release was evaluated by plotting the log percentage of drug released versus log time according to the Korsmeyer-Peppas equation. The exponent ' $n$ ' indicates the mechanism of drug release calculated through the slope of the straight line.

$$
\mathrm{Mt} / \mathrm{M} \infty=\mathrm{K} \text { tn }
$$

Where, Mt/ Mळ is a fraction of drug released at a time ' $t$ ' $k$ represents a constant, and ' $n$ ' is the diffusional exponent, which characterizes the type of release mechanism during the dissolution process. For non-Fickian release, the value of $n$ falls between 0.5 and 1.0.

While in case of Fickian diffusion, $\mathrm{n}=0.5$; for zero-order release (case II transport), $\mathrm{n}=1$; and for super case II transport, $n>1$. In this model, a plot of $\log (\mathrm{Mt} / \mathrm{M} \infty)$ versus $\log$ (time) is linear.

\section{Hixson-Crowell Release Model:}

$$
(100-Q t) 1 / 3=1001 / 3-\text { KHC.t }
$$

Where $\mathrm{k}$ is the Hixson-Crowell rate constant.

Hixson-Crowell's model describes the release of drugs from an insoluble matrix through main erosion. (Where there is a change in surface area and diameter of particles or tablets). 
RESULTS AND DISCUSSION:

Drug - Excipient Compatibility Studies: There was no disappearance of any characteristics peak in the FTIR spectrum of drugs and the polymers used. This shows that there is no chemical interaction between the drug and the polymers used. The presence of peaks at the expected range confirms that the materials taken for the study are genuine, and there were no possible interactions. Lornoxicam also presents in the physical mixture, which indicates that there is no interaction between the drug and the polymers, which confirms the stability of the drug. The results are shown in Fig. 1 and 2 .

\section{Fourier Transform-Infrared Spectroscopy:}

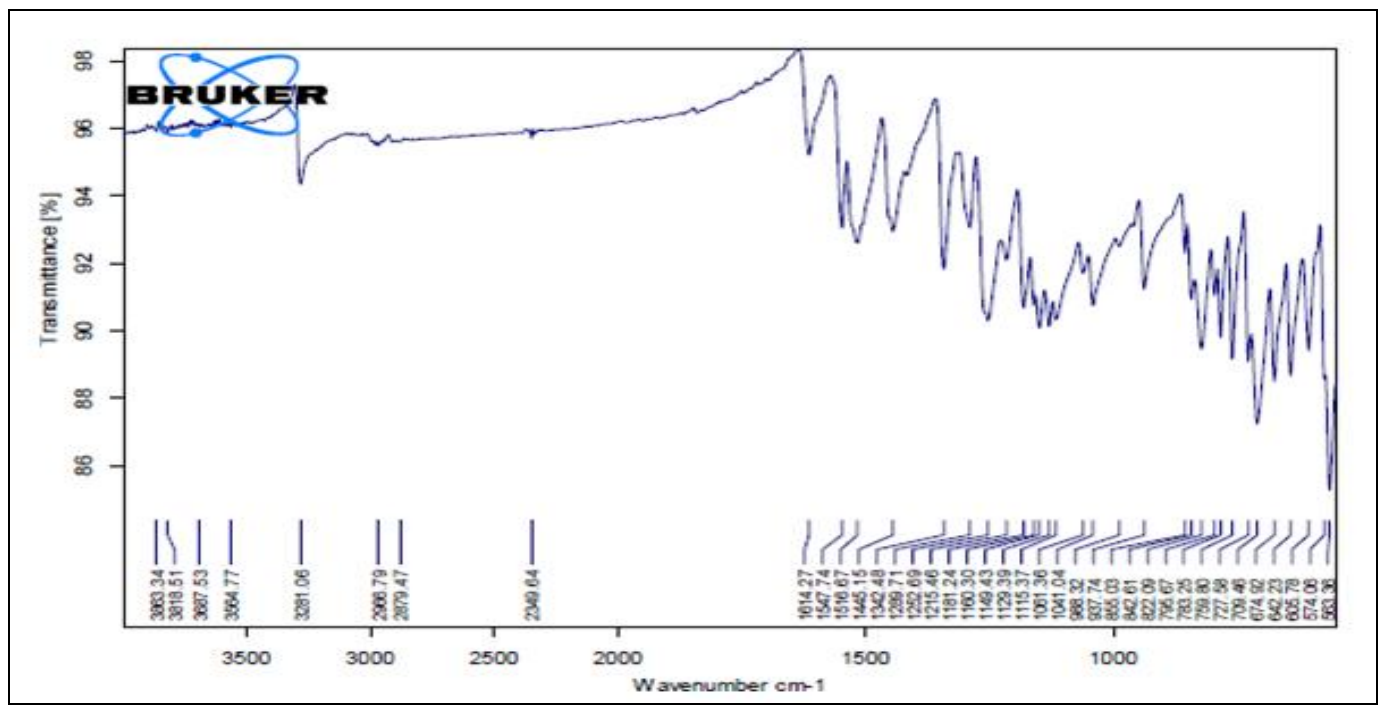

FIG. 1: FTIR SPECTRUM OF LORNOXICAM PURE DRUG

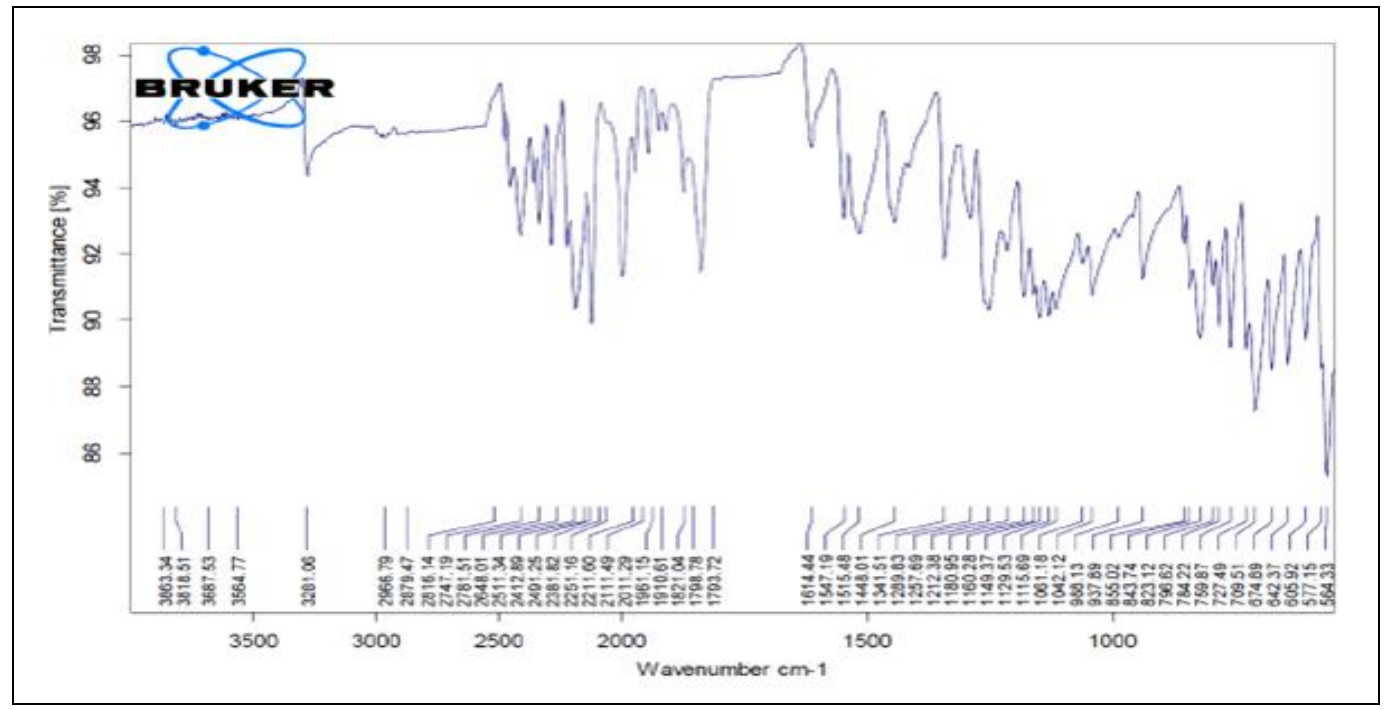

FIG. 2: FTIR SPECTRUM OF OPTIMISED FORMULATION

Pre-formulation Parameters of Powder Blend: Tablet powder blend was subjected to various preformulation parameters. The angle of repose values indicates that the powder blend has good flow properties. The bulk density of all the formulations was found to be in the range of $0.48 \pm 0.09$ to 0.58 $\pm 0.01\left(\mathrm{gm} / \mathrm{cm}^{3}\right)$, showing that the powder has good flow properties. The tapped density of all the formulations was found to be in the range of 0.57 \pm 0.06 to $0.69 \pm 0.05$, showing the powder has good flow properties. The compressibility index of all the formulations was found to be ranging from 14 to 18 , which shows that the powder has good flow properties. All the formulations have shown the Hausner ratio ranging between 0 to 1.25 , indicating the powder has good flow properties. The results are shown in Table 2. 
TABLE 2: PRE-FORMULATION PARAMETERS OF CORE BLEND

\begin{tabular}{cccccc}
\hline Formulation code & Angle of Repose & Bulk density $(\mathbf{g m} / \mathbf{m l})$ & Tapped density $(\mathbf{g m} / \mathbf{m l})$ & Carr's index (\%) & Hausner's Ratio \\
\hline F1 & $25.01 \pm 0.21$ & $0.49 \pm 0.05$ & $0.57 \pm 0.06$ & $14.03 \pm 0.01$ \\
F2 & $26.8 \pm 0.35$ & $0.56 \pm 0.04$ & $0.67 \pm 0.08$ & $16.41 \pm 0.00$ & $1.16 \pm 0.02$ \\
F3 & $27.7 \pm 0.42$ & $0.52 \pm 0.09$ & $0.64 \pm 0.02$ & $18.75 \pm 0.09$ \\
F4 & $25.33 \pm 0.48$ & $0.54 \pm 0.05$ & $0.64 \pm 0.04$ & $15.62 \pm 0.05$ \\
F5 & $25.24 \pm 0.52$ & $0.53 \pm 0.02$ & $0.65 \pm 0.05$ & $18.46 \pm 0.09$ & $1.23 \pm 0.06$ \\
F6 & $28.12 \pm 0.35$ & $0.56 \pm 0.03$ & $0.66 \pm 0.02$ & $15.15 \pm 0.02$ & $1.22 \pm 0.07$ \\
F7 & $27.08 \pm 0.47$ & $0.58 \pm 0.01$ & $0.69 \pm 0.05$ & $15.94 \pm 0.01$ & $1.18 \pm 0.05$ \\
F8 & $25.12 \pm 0.51$ & $0.48 \pm 0.09$ & $0.57 \pm 0.05$ & $15.78 \pm 0.05$ & $1.18 \pm 0.06$ \\
F9 & $26.45 \pm 0.65$ & $0.54 \pm 0.02$ & $0.65 \pm 0.04$ & $16.92 \pm 0.04$ & $1.2 \pm 0.07$ \\
\hline
\end{tabular}

TABLE 3: IN-VITRO QUALITY CONTROL PARAMETERS

\begin{tabular}{cccccc}
\hline Formulation codes & Average weight $\mathbf{( m g )}$ & Hardness $\mathbf{( k g / \mathbf { c m } ^ { 2 } )}$ & Friability (\%loss) & Thickness $(\mathbf{m m})$ & Drug content $(\boldsymbol{\%})$ \\
\hline F1 & $99.8 \pm 1.48$ & $4.5 \pm 0.06$ & $0.40 \pm 0.08$ & $2.79 \pm 0.05$ & $95.1 \pm 0.15$ \\
F2 & $95.32 \pm 1.42$ & $5.0 \pm 0.05$ & $0.19 \pm 0.05$ & $3.08 \pm 0.06$ & $94.8 \pm 0.24$ \\
F3 & $105.88 \pm 2.28$ & $4.5 \pm 0.07$ & $0.08 \pm 0.04$ & $3.05 \pm 0.06$ & $91.34 \pm 0.32$ \\
F4 & $101.72 \pm 0.74$ & $4.4 \pm 0.03$ & $0.29 \pm 0.05$ & $2.93 \pm 0.05$ & $96.55 \pm 0.41$ \\
F5 & $97.42 \pm 0.85$ & $4.5 \pm 0.05$ & $0.30 \pm 0.05$ & $2.79 \pm 0.07$ & $94.13 \pm 0.15$ \\
F6 & $95.02 \pm 0.88$ & $4.7 \pm 0.01$ & $0.72 \pm 0.03$ & $2.76 \pm 0.01$ & $99.30 \pm 0.18$ \\
F7 & $100.9 \pm 1.01$ & $4.3 \pm 0.03$ & $0.41 \pm 0.04$ & $2.74 \pm 0.06$ & $94.82 \pm 0.32$ \\
F8 & $104.48 \pm 0.37$ & $4.9 \pm 0.04$ & $0.20 \pm 0.04$ & $2.75 \pm 0.04$ & $95.86 \pm 0.45$ \\
F9 & $103.4 \pm 1.19$ & $4.5 \pm 0.06$ & $0.19 \pm 0.04$ & $2.76 \pm 0.06$ & $96.55 \pm 0.25$ \\
\hline
\end{tabular}

Quality Control Parameters For tablets: Tablet quality control tests such as weight variation, hardness, and friability, thickness, and drug release studies in different media were performed on the compression coated tablet. The results are shown in Table 3.

Weight Variation Test: Tablets of each batch were subjected to weight variation test; the difference in weight and percent deviation was calculated for each tablet. The average weight of the tablet is approximately in a range of $295.02 \pm$ 0.883 to $05.88 \pm 2.28 \mathrm{mg}$; the results of the test showed that the tablet weights were within the pharmacopeia limit.

Hardness Test: Hardness of the three tablets of each batch was checked by using Monsanto hardness tester. The results showed that the hardness of the tablets is in a range of $4.3 \pm 0.03$ to $5.0 \pm 0.05 \mathrm{~kg} / \mathrm{cm}^{2}$, which was within IP limits.

Thickness: Thickness of three tablets of each batch was checked by using Vernier Caliper and data shown. The result showed that the thickness of the tablet is raging from $2.74 \pm 0.06$ to $3.08 \pm 0.06$ mm.

Friability: Tablets of each batch were evaluated for percentage friability and. The average friability of all the formulations lies in the range of $0.08 \pm$ 0.04 to $0.72 \pm 0.03$, which was less than $1 \%$ as per the official requirement of IP indicating a good mechanical resistance of tablets. All the parameters such as weight variation, friability, hardness, thickness, and drug content were found to be within limits

Drug Content: Drug content studies were performed for the prepared formulations. From the drug content studies, it was concluded that all the formulations were showing the $\%$ drug content values within $94.8-96.5 \%$. All the parameters such as weight variation, friability, hardness, thickness, and drug content were found to be within limits. The results are shown in Tables 4, 5, 6, and Fig. 3, $4,5$.

In-vitro Drug Release Studies:

TABLE 4: DISSOLUTION DATA OF LORNOXICAM TABLETS PREPARED WITH GUAR GUM IN DIFFERENT CONCENTRATIONS

\begin{tabular}{cccc}
\hline Time & \multicolumn{3}{c}{ Cumulative Percent Drug Dissolved } \\
\cline { 2 - 4 }$(\mathbf{h})$ & F1 & F2 & F3 \\
\hline 0 & 0 & 0 & 0 \\
0.5 & 28.18 & 23.93 & 18.4 \\
1 & 34.47 & 31.68 & 22.3 \\
2 & 50.38 & 39.77 & 29.5 \\
3 & 79.33 & 44.51 & 32.3 \\
4 & 84.38 & 52.97 & 41.3 \\
5 & 89.45 & 59.84 & 52.6 \\
6 & 93.4 & 65.81 & 59.4 \\
7 & 96.8 & 70.91 & 65.2 \\
8 & 99.2 & 78.29 & 72.3 \\
9 & & 83.94 & 79.5 \\
10 & & 89.88 & 82.5 \\
11 & & 93.82 & 89.1 \\
12 & & 99.65 & 91.2 \\
\hline
\end{tabular}


TABLE 5: DISSOLUTION DATA OF LORNOXICAM TABLETS PREPARED WITH XANTHAN GUM IN DIFFERENT CONCENTRATIONS

\begin{tabular}{cccc}
\hline \multirow{2}{*}{$\begin{array}{c}\text { Time } \\
\text { (h) }\end{array}$} & \multicolumn{3}{c}{ Cumulative Percent Drug Dissolved } \\
\cline { 2 - 4 } & F4 & F5 & F6 \\
\hline 0 & 0 & 0 & 0 \\
0.5 & 37.25 & 34.24 & 30.62 \\
1 & 48.26 & 43.37 & 34.86 \\
2 & 54.16 & 48.63 & 40.35 \\
3 & 71.01 & 65.04 & 48.45 \\
4 & 88.26 & 70.25 & 54.80 \\
5 & 99.10 & 87.33 & 59.25 \\
6 & & 94.41 & 65.24 \\
7 & & 98.56 & 70.73 \\
8 & & & 78.34 \\
9 & & & 85.52 \\
10 & & & 99.17 \\
11 & & & \\
12 & & & \\
\hline
\end{tabular}

TABLE 6: DISSOLUTION DATA OF LORNOXICAM TABLETS PREPARED WITH CARBOPOL IN DIFFERENT CONCENTRATIONS

\begin{tabular}{|c|c|c|c|}
\hline \multirow{2}{*}{$\begin{array}{l}\text { Time } \\
\text { (h) }\end{array}$} & \multicolumn{3}{|c|}{ Cumulative Percent Drug Dissolved } \\
\hline & F7 & F8 & F9 \\
\hline 0 & 0 & 0 & 0 \\
\hline 0.5 & 8.2 & 3.2 & 1.9 \\
\hline 1 & 13.2 & 8.9 & 2.2 \\
\hline 2 & 16.3 & 12.3 & 8.3 \\
\hline 3 & 22.4 & 17.4 & 12.3 \\
\hline 4 & 26.3 & 19.3 & 17.4 \\
\hline 5 & 29.5 & 22.4 & 19.3 \\
\hline 6 & 32.8 & 25.6 & 22.4 \\
\hline 7 & 38.4 & 32.3 & 25.6 \\
\hline 8 & 42.5 & 37.6 & 32.9 \\
\hline 9 & 48.15 & 42.8 & 37.5 \\
\hline 10 & 56.36 & 52.6 & 42.7 \\
\hline 11 & 73.46 & 62.3 & 52.3 \\
\hline 12 & 85.51 & 72.3 & 62.8 \\
\hline
\end{tabular}

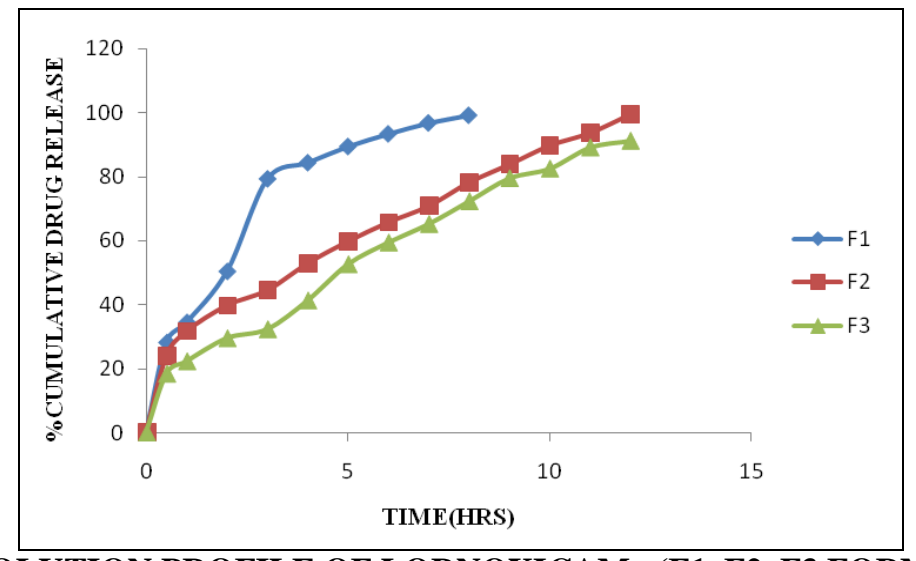

FIG. 3: DISSOLUTION PROFILE OF LORNOXICAM (F1, F2, F3 FORMULATIONS)

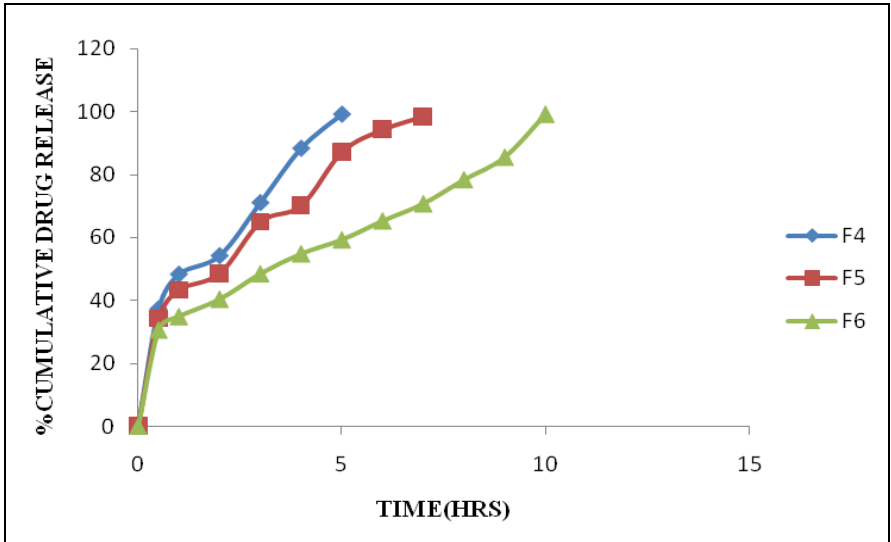

FIG. 4: DISSOLUTION PROFILE OF LORNOXICAM (F4, F5, F6 FORMULATIONS)

From the dissolution data, it was revealed that formulations prepared with xanthan gum did not retard the drug release up to $12 \mathrm{~h}$. Hence, those formulations did not take into consideration. Formulations prepared with carbopol retard the drug release more than $12 \mathrm{~h}$. These formulations also did not take into consideration. Formulations

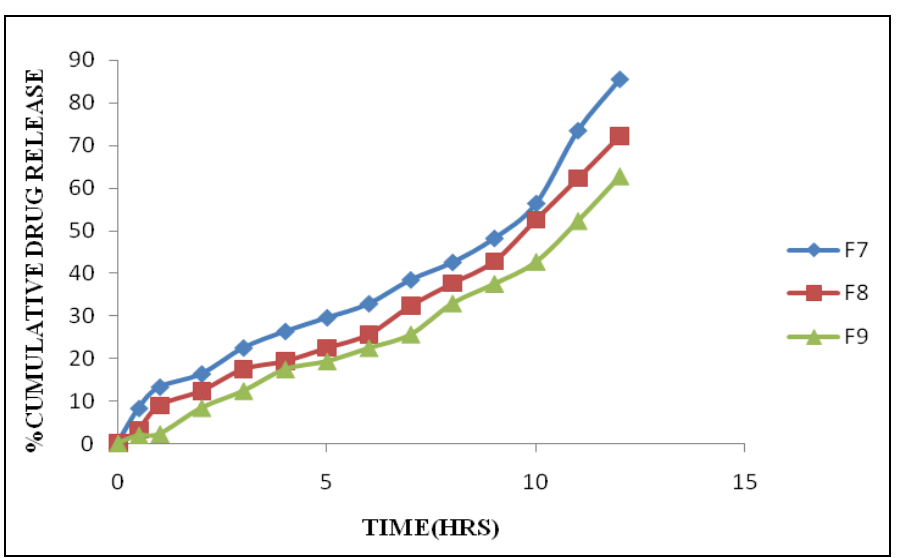

FIG. 5: DISSOLUTION PROFILE OF LORNOXICAM (F7, F8, F9 FORMULATIONS)

prepared with Guar gum were revealed that an increase in the concentration retards the drug release.

Among all formulations, F2 formulation was considered as optimized formulation. It was shown a $99.65 \%$ drug release at $12 \mathrm{~h}$. 
Application of Release Rate Kinetics to Dissolution Data:

TABLE 7: RELEASE RATE KINETICS TO DISSOLUTION DATA

\begin{tabular}{|c|c|c|c|c|c|c|c|c|c|}
\hline $\begin{array}{c}\text { Cumulative } \\
\text { (\%) Release } \\
\text { Q }\end{array}$ & $\begin{array}{l}\text { Time } \\
\text { ( T ) }\end{array}$ & $\begin{array}{l}\text { Root } \\
(\mathrm{T})\end{array}$ & $\begin{array}{l}\text { Log }(\%) \\
\text { Release }\end{array}$ & $\begin{array}{l}\text { Log } \\
(\mathrm{T})\end{array}$ & $\begin{array}{c}\text { LOG (\%) } \\
\text { Remain }\end{array}$ & $\begin{array}{c}\text { Release Rate } \\
\text { (Cumulative \% } \\
\text { Release / t) }\end{array}$ & $\begin{array}{c}\text { 1/CUM\% } \\
\text { Release }\end{array}$ & $\begin{array}{c}\text { PEPPAS } \\
\log Q / 100\end{array}$ & $\begin{array}{c}\% \text { Drug } \\
\text { Remaining }\end{array}$ \\
\hline 0 & 0 & 0 & & & 2.000 & & & & 100 \\
\hline 31.68 & 1 & 1.000 & 1.501 & 0.000 & 1.835 & 31.680 & 0.0316 & -0.499 & 68.32 \\
\hline 39.77 & 2 & 1.414 & 1.600 & 0.301 & 1.780 & 19.885 & 0.0251 & -0.400 & 60.23 \\
\hline 44.51 & 3 & 1.732 & 1.648 & 0.477 & 1.744 & 14.837 & 0.0225 & -0.352 & 55.49 \\
\hline 65.81 & 6 & 2.449 & 1.818 & 0.778 & 1.534 & 10.968 & 0.0152 & -0.182 & 34.19 \\
\hline 70.91 & 7 & 2.646 & 1.851 & 0.845 & 1.464 & 10.130 & 0.0141 & -0.149 & 29.09 \\
\hline 78.29 & 8 & 2.828 & 1.894 & 0.903 & 1.337 & 9.786 & 0.0128 & -0.106 & 21.71 \\
\hline 83.94 & 9 & 3.000 & 1.924 & 0.954 & 1.206 & 9.327 & 0.0119 & -0.076 & 16.06 \\
\hline 89.88 & 10 & 3.162 & 1.954 & 1.000 & 1.005 & 8.988 & 0.0111 & -0.046 & 10.12 \\
\hline 93.82 & 11 & 3.317 & 1.972 & 1.041 & 0.791 & 8.529 & 0.0107 & -0.028 & 6.18 \\
\hline
\end{tabular}

Various models were tested for explaining the kinetics of drug release. To analyze the mechanism of the drug release rate kinetics of the dosage form, the obtained data were fitted into zero-order, firstorder, Higuchi, and Korsmeyer-Peppas release model.

\section{Release Kinetics Data for Optimised Formulation:}

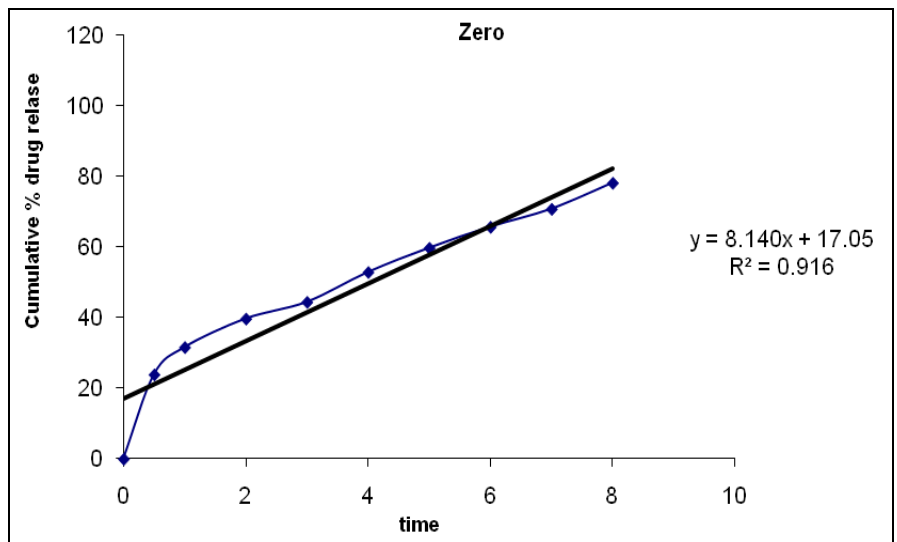

FIG. 6: ZERO ORDER RELEASE KINETICS GRAPH

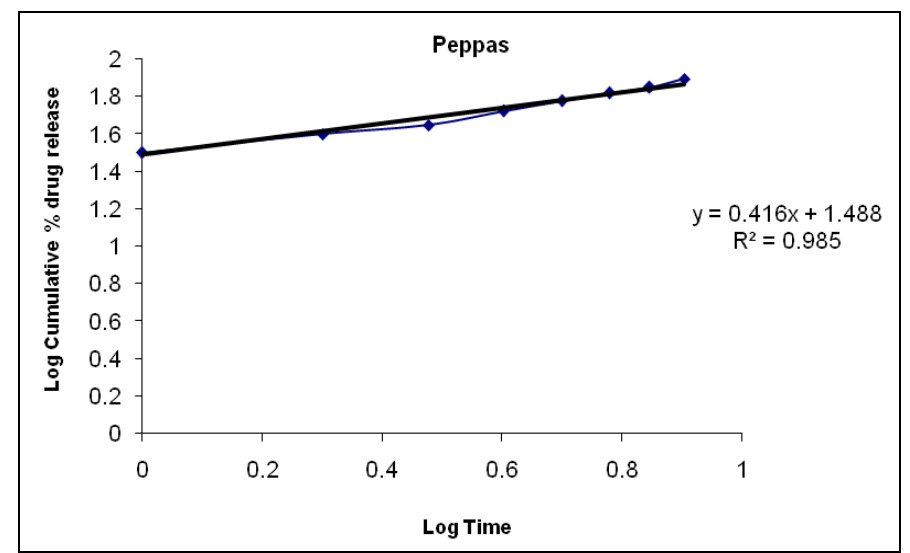

FIG. 8: KARSMAYER PEPPAS GRAPH

From the above graphs, it was evident that the formulation F2 was followed Higuchi release kinetics.

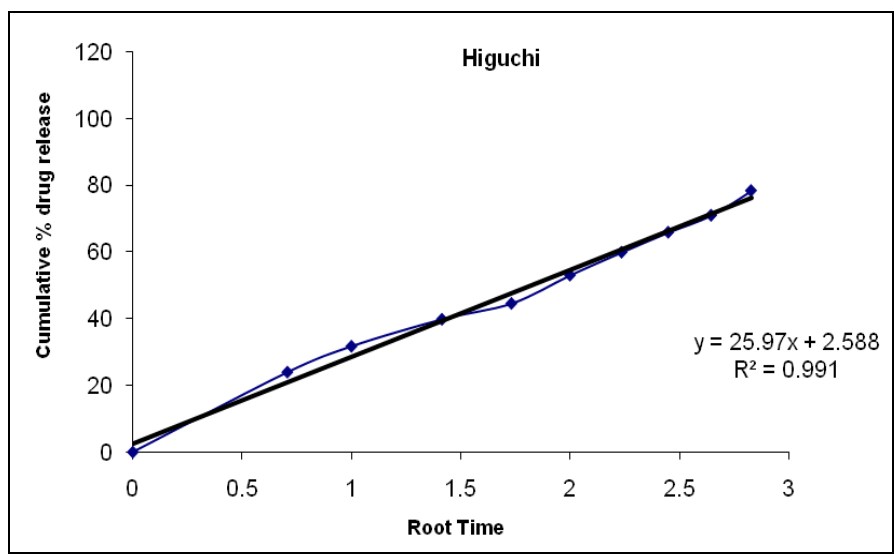

FIG. 7: HIGUCHI RELEASE KINETICS GRAPH

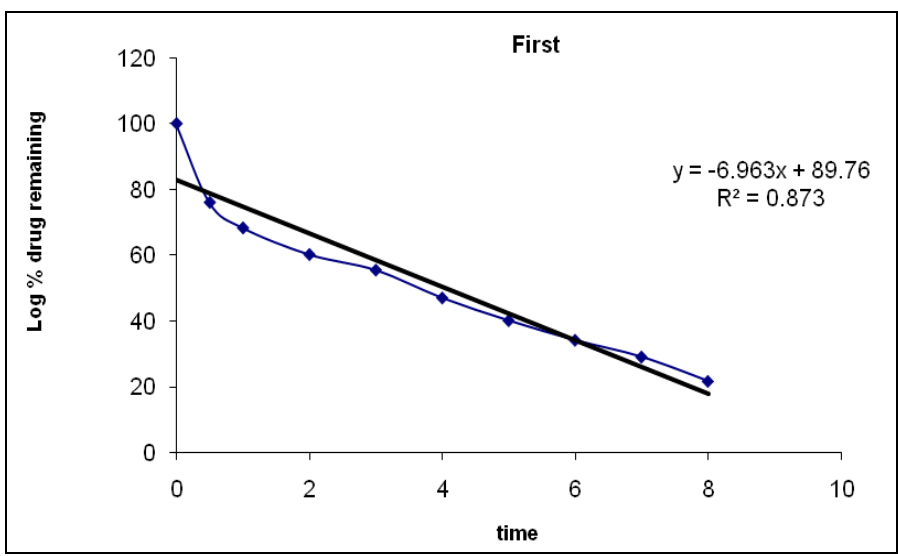

FIG. 9: FIRST ORDER RELEASE KINETICS GRAPH

CONCLUSION: The present investigation was carried out for controlling the drug release up to 12 h. 
For controlling the drug release, polymers used such as Guar Gum, Xanthan Gum, and Carbopol 934. From the investigation, studies were found following: Standard graph was given that regression analysis $\mathrm{R} 2$ value was 0.999 in both 0.1 $\mathrm{N} \mathrm{HCl}$ and $\mathrm{pH} 6.8$ phosphate buffer.

FTIR results were shown good compatibility between drugs and excipients. All the pre and postcompression studies such as Bulk density, Tapped density, Angle of repose, Carr's index, Hausner's ratio, Weight variation, Thickness, Hardness, Drug content were found to be within limits.

In-vitro drug release studies revealed that among all formulations, F2 formulation was considered as an optimized formulation, which contains guar gum as a polymer in the concentration of $4 \mathrm{mg}$. Drug release kinetic studies were done for optimized formulation. It was followed Higuchi release kinetics.

\section{ACKNOWLEDGEMENT: Nil}

\section{CONFLICTS OF INTEREST: Nil}

\section{REFERENCES:}

1. Nokhodchi, Raja S, Patel P and Asare-Addo K: The role of oral controlled release matrix tablets in drug delivery systems. Bioimpacts 2012; 2(4): 175-87.

2. Rathore AS, Jat RC, Sharma N and Tiwari R: An overview: matrix tablet as controlled drug delivery system. International Journal of Research and Develoment in Pharmacy and Life Sciences 2013; 2(4): 482-92.

3. Bhalla N, Arsh D and Goswami M: An overview on various approaches to oral controlled drug delivery system via gastoretentive drug delivery system. Int Res J Pharm 2012; 3(4): 128-33.

4. Maggi L, Bruni R and Conte U: High molecular weight polyethylene oxides as an alternative to HPMC controlled release dosage forms. Int J Pharm 2000; 195(1-2): 229-38.

5. Vyas SP and Khar RK: Controlled drug delivery concepts and advances. CBS Publishers 2001; 1: 1-53.
6. Siegel RA and Rathbone MJ: Departments of pharmaceutics and biomedical engineering: chapter 2: overview of controlled release mechanisms. Minnepolis 2012; 19-43.

7. Bramhanker DM and Jaiswal SB: Controlled release medications. biopharmaceutics and pharmacokinetics a treatise. Vallabh Prakashan 1995; 2: 335-75.

8. Patel H, Panchal DR, Patel U, Brahmbhatt T and Suthar M: Matrix type drug delivery system: a review. Journal of Pharma Science and Bioscientific Res 2011; 1(3): 143-51.

9. Jadhav AS and Tarkase KN: Formulation aspects with an comparative influence of different parameters over matrix tablet. International Journal of Pharmaceutical Review and Research 2012; 3(2): 33-42.

10. Hemnani M, Patel U, Patel G, Daslaniya D and Shah A: Matrix tablets: a tool of controlled drug delivery. American J of Pharmatech Research 2011; 1(4): 2249-87.

11. Mamidala RK, Ramana V, Sandeep G, Lingam M, Gannu $\mathrm{R}$ and Yamsani MR: Factors influencing the design and performance of oral sustained/ controlled release dosage forms. International Journal of Pharmaceutical Sciences and Nanotechnology 2009; 3(2): 583-94.

12. Shen SI, Jasti BR and Li X: Standard handbook of biomedical engineering and design: chapter 22- design of controlled- release drug delivery systems. Mc Graw-Hill 2004; 1-14.

13. Chien YW: Controlled drug delivery systems. Novel drug delivery systems. Marcel Dekker 1992; 2: 139-96.

14. Robinson JR and Jantzen GM: Controlled-release drug delivery systems- fundamentals and applications. Marcell Dekker 1995; 575-09.

15. Sunilkamboj: Matrix tablets- an important tool for oral controlled release dosage forms. Pharma Info 2009; 23-25: 1-29.

16. Kumar KS, Rao RT and Jayaveera KN: Matrix tablets as controlled drug delivery. Indo American Journal of Pharmaceutical Research 2011; 1(5): 407-414.

17. TR Dash and Verma P: Matrix tablets: an approach towards oral extended release drug delivery. International Journal of Pharma Res and Review 2013; 2(2): 12-24.

18. Nisha $S$, Mathew $G$ and Lincy J: Matrix tablets: an effective way for oral controlled release drug delivery. Iranian Journal of Pharma Sciences 2012; 8(3): 165-70.

19. Borguist $\mathrm{P}$, Korner A and Larsson A: A model for the drug release from a polymeric matrix tablets-effect of swelling and dissolution. J Control Release 2006; 113: 216-25.

20. Kirankumar S, Ramarao T, Bikshapathi DBRN and Jayaveera KN: Controlled release formulation development and evaluation of felodipine matrix tablets by using hydrophobic polymers. International Journal of Pharmaceutical Sciences and Research 2013; 4(1): 506-11.

How to cite this article:

Kumar PS and Sravani A: Formulation and in-vitro evaluation of controlled release matrix tablets of lornoxicam. Int J Pharm Sci \& Res 2020; 11(6): 2793-00. doi: 10.13040/IJPSR.0975-8232.11(6).2793-00.

All () 2013 are reserved by the International Journal of Pharmaceutical Sciences and Research. This Journal licensed under a Creative Commons Attribution-NonCommercial-ShareAlike 3.0 Unported License.

This article can be downloaded to Android OS based mobile. Scan QR Code using Code/Bar Scanner from your mobile. (Scanners are available on Google Play store) 